\title{
Innovation and humanization in child care: professionals from Ceará who make the difference
}

Lucas Giannini de Oliveira Conrado Arruda 1*, Marília Freitas Santana 1, Gabriele Sousa Barbosa 1, Amanda Medeiros de Lima 2, Igor Moreira Veras 3, Liane Carvalho de Brito de Souza 1, Flávio Lobo Maia 1, Rodrigo José Alencar de Castro 1, Danielle Moreira Collares 4, Josenília Maria Alves Gomes 1

1 Walter Cantídio University Hospital, Federal University of Ceara, UFC, Fortaleza, CE, Brazil.

2 University of Buenos Aires, UBA, Buenos Aires, Argentina.

${ }^{3}$ Integrated Regional Center of Oncology of Ceara, CRIO, Fortaleza, CE, Brazil.

${ }^{4}$ Albert Sabin Children's Hospital, HIAS, Fortaleza, CE, Brazil.

*Corresponding author: Lucas Giannini de Oliveira Conrado Arruda. R. Pastor Samuel Munguba, 1290 - Rodolfo Teófilo. Zip Code: 60430-372-Ceara, CE, Brazil. Phone:+55 (85) 3366-8163. E-mail: lucas_jko@hotmail.com.

Research Ethics Committee Approval (if necessary): Not applicable.

Received on: Oct 10, 2021. Accepted on: Oct 25, 2021. Available online: Nov 5, 2021.

Abstract
Within a regional context, these experience reports cited the practice of some health
professionals, they did a wonderful work in theirs pediatric centeres which are
reference in pediatric care. In this context of affection and humanity, we highlight
examples of people who word with love in the art of caring. And this article shares
theirs improvements, indeed, we hope these achievements enlighten other people.
Keywords: Humanization; Assistance; Pediatrics; Patient Care; Creativity.

\section{Introduction}

Nowadays, the taking care and supportive care mean a spark of humanization for children. They need refuge to their staying in hospital. In other hand, the automatization and standardization of care and the fragmentation of work and care pathways, often linked to time and staff rationing, can lead to a dehumanization and depersonalization of care. In pediatric, this last conception broke the pediatric/patient/parents relationship.
The patient-centered care has been developed as an alternative to the traditional, paternalistic, diseasecentered model. Instead of focusing primarily on symptoms during the clinical encounter, the physician shows compassion and empathy towards the patient, respects her/his individual values and their family [1].

We share some approaches in our northeast health community has been improved some points of pediatric care. These actions have two point-of-view, 
they enhance the taking care and show how health team desires better pediatric care. We take care of poorest children in these pediatric hospitals, which actions allow happiness and comfort. Besides all those worst health situation and depressed conditions, our team managed their imagination to create news circumstances for those little ones.

Many health professionals stand out for making a difference in the lives of children who are terrified when undergoing some type of medical procedure. About this, regardless of the size of the procedure, during the stress caused by what is unknown to them, children, especially under the age of six, exhibit catastrophizing phenomena.

In this context, children with anxious behavior - with insecure family members, coupled with lack of information, will have a major setback; whether for simple and painless medical procedures, or for invasive and painful procedures. In the case of diagnostic procedures that require immobility of the child or surgical procedures, we will have the figure of the anesthesiologist. This professional, in turn, makes up the team that promotes the best care and confort for children and their families.

\section{Experience Report}

In the countryside of the state of Minas Gerais he was born, and in the city of Campinas, in the state of São
Paulo, this talented philosopher and writer Rubem Alves, who has a son, Sergio Nopper Alves, who is an anesthesiologist. In his chronicle, entitled "O Anestesista" (The Anesthesiologist), he quotes:

He told me about a young woman who was terrified. The fear was enormous. She couldn't calm down. Having exhausted all maternal resources, a mystical enlightenment came to her. "Do you believe in guardian angels?" he asked the little girl. The girl replied, "I do". And he concluded, "For tomorrow I will be the guardian angel watching over your sleep". She was reassured.

And that is, however, the function of the pediatric anesthesiologist: to comfort, assist, and reassure everyone; besides making it possible for something good to happen to someone - be it a surgery, an exam, or some procedure that requires their care. On the subject of child comfort, ABRALE (Brazilian Association of Lymphoma and Leukemia) helps all over Brazil in the fight against children's cancer. This association has a great ally: the professionals involved at the Maurício de Sousa Institute. They do a great job in the donation campaigns involving the Turma da Mônica characters, and in the pain assessment figures and symptoms related to children. This and other information can 
be accessed at Protejo Dodói - dodoi/ (Figure 1).

https://www.abrale.org.br/projeto-dodoi/kit-
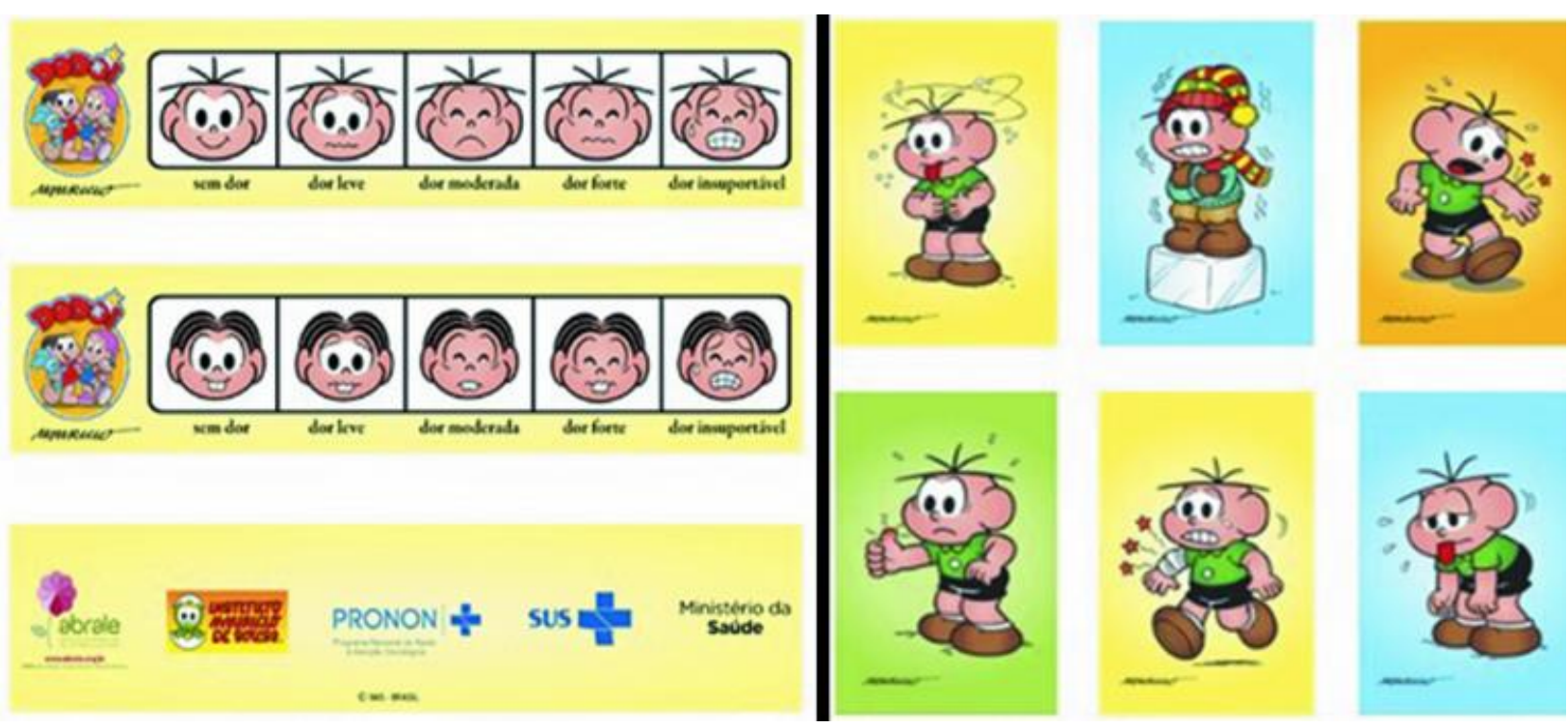

Figure 1. Turma da Mônica's pain scale and diagnostic cards: the child chooses an illustration that symbolizes his or her condition.

The figures are illustrations with the Mônica's Gang, representing feelings and sensations such as tingling, high temperature, and shortness of breath. In addition, they seek to provide information for the doctor and the care team. In our midst, professionals from Ceará have also become protagonists in child care. In this regard, I interviewed some names, and I quote their respective experiences.

\section{Dr. Magno Erick Peixoto, otorhinolaryngologist at Otos Clinic}

In an interview with Dr. Magno Erick Peixoto, otorhinolaryngologist at
Otos Clinic, he reports that: "I've always been very interested in drawing, pencil, paper and imagination. Once in a while I was doodling. Meanwhile, I had to dedicate a lot of time to my studies, so this practice ended up being put aside. As you know, otolaryngology and pediatrics go hand in hand; here in this unit and in the other units of the Otos Clinic, we always have the two specialties together. Between one thing and another, friends always asked me to do some engraving or something of the sort. Some years ago I did this one for a children's hospital" (Figure 2). 


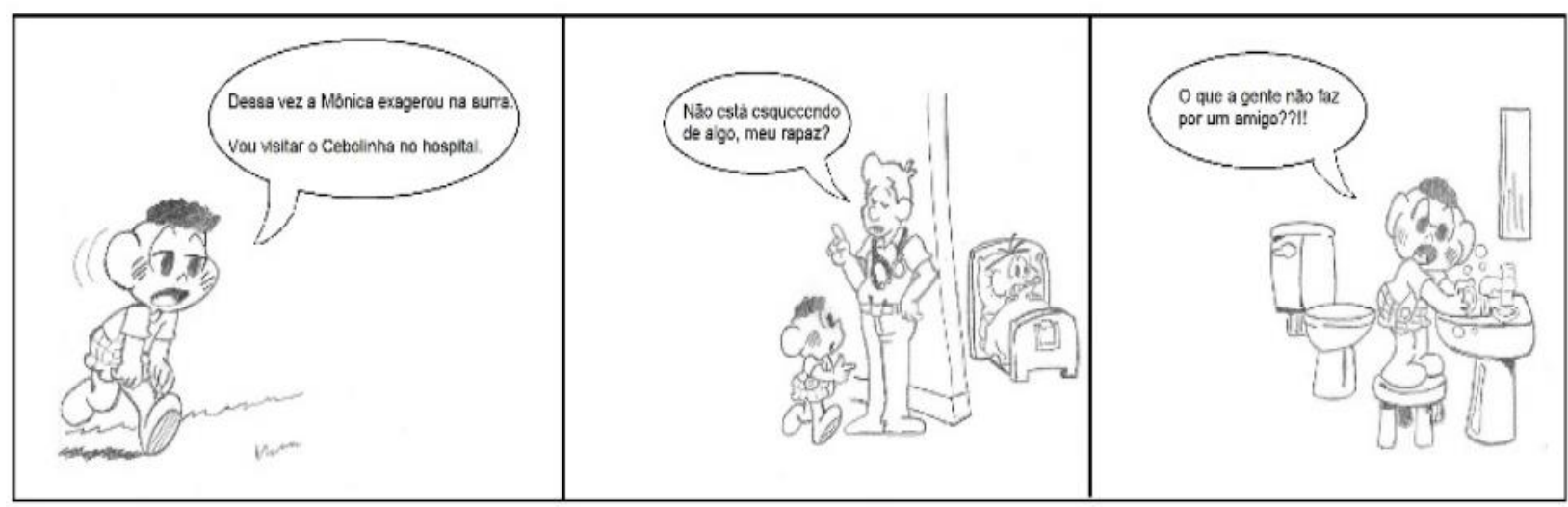

Figure 2. Incentive for professionals and companions to always wash their hands, in a campaign against hospital infection.

Here at the Otos clinic, the humanization of children is a priority. The administration is always recycling for everyone who works with children; there is a special space for children, they have a very playful playroom. In meetings with my partners and the administration, the children's theme for our clinics was left to me. However, it was not my choice; it was just that pressure: to come up with something nice and beautiful for the little ones. Then I thought: what is the moment when children complain the most? I had no doubt - it is during the exam - even with all the niceties, there is a lot of crying. So, I imagined a complete kit. Before the doctor's appointment, I would make a little theater with them and demonstrate on the doll. It is not very different from the games I used to play with my first son, Matthew. In this way, I put everything together: the dolls, which were the doctors, the girl and the boy, and the examination chair. So, the inspiration for Dr. Otos, despite the jokes from colleagues, was not from anyone at work, it was from my first son, Matthew.

So, I put Dr. Otos as the main character for the didactic and play therapy material. We have made the model with the dolls, the examination chair, and the ENT material. At the end of the exams, like rhinoscopy or nasofibrocopy, the child receives his or her certificate of courage (Figure 3).

\section{Dr. Filipe Lino Bastos Vasconcelos, anesthesiologist at Walter Cantídio University Hospital (HUWC)}

According to Dr. Filipe Lino, the idea of using the 3D glasses came from his children. The boys love these new technologies. As a good father, he had to update himself as well. Furthermore, he researched in scientific articles this tool 
that has been used in anesthesia for imaging exams, such as chest and abdomen computed tomography and ultrasonography $3 \mathrm{D}$ reality consists in the use of virtual reality glasses, which are connected to the cell phone of the patients themselves, their guardians, or the doctor accompanying the child". Dr. Filipe uses this technology in the imaging sector of HUWC. He claims to observe better results when the technique is used in procedures with children aged 6 to 10 years. Thus, in the vast majority of patients in this age group, this tool becomes so interesting that it is not necessary to use sedation on these children. In this perspective, he also reports that the use of 3D reality videos stimulates the brain to release adrenaline, motivated by radical sensations such as in a roller coaster ride. At this point it is possible to have a decrease in pain perception during venipuncture.

Therefore, he mentions with great pride that he uses his own children's equipment: "it's like playing with our children...Unfortunately, we health professionals work so hard, we barely have time to be with our own children. Hopefully the people who take care of ours will have the same affection we have for other people's children" (Figure 4).

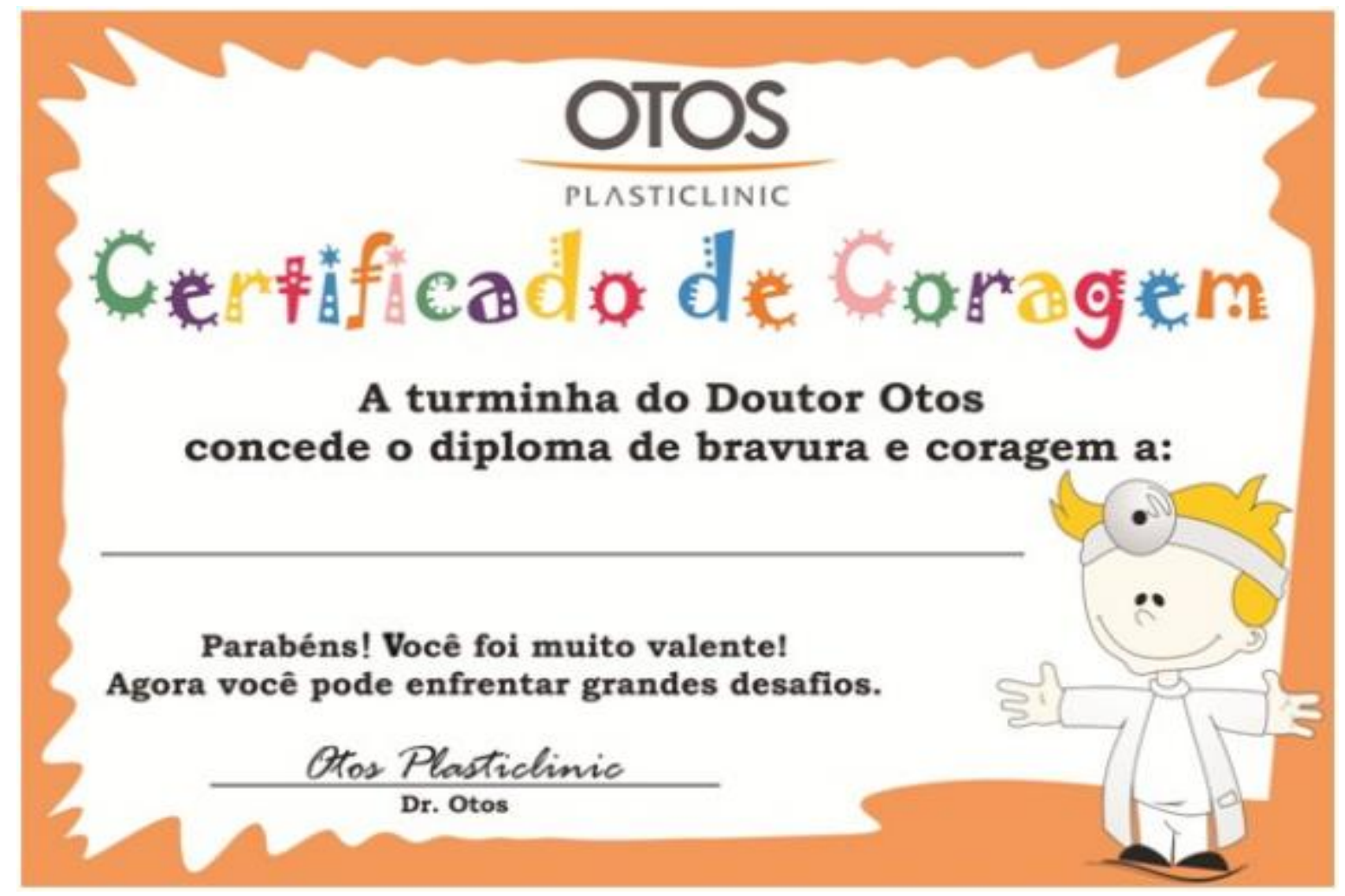

Figure 3. Dr. Otos's certificate of courage. 

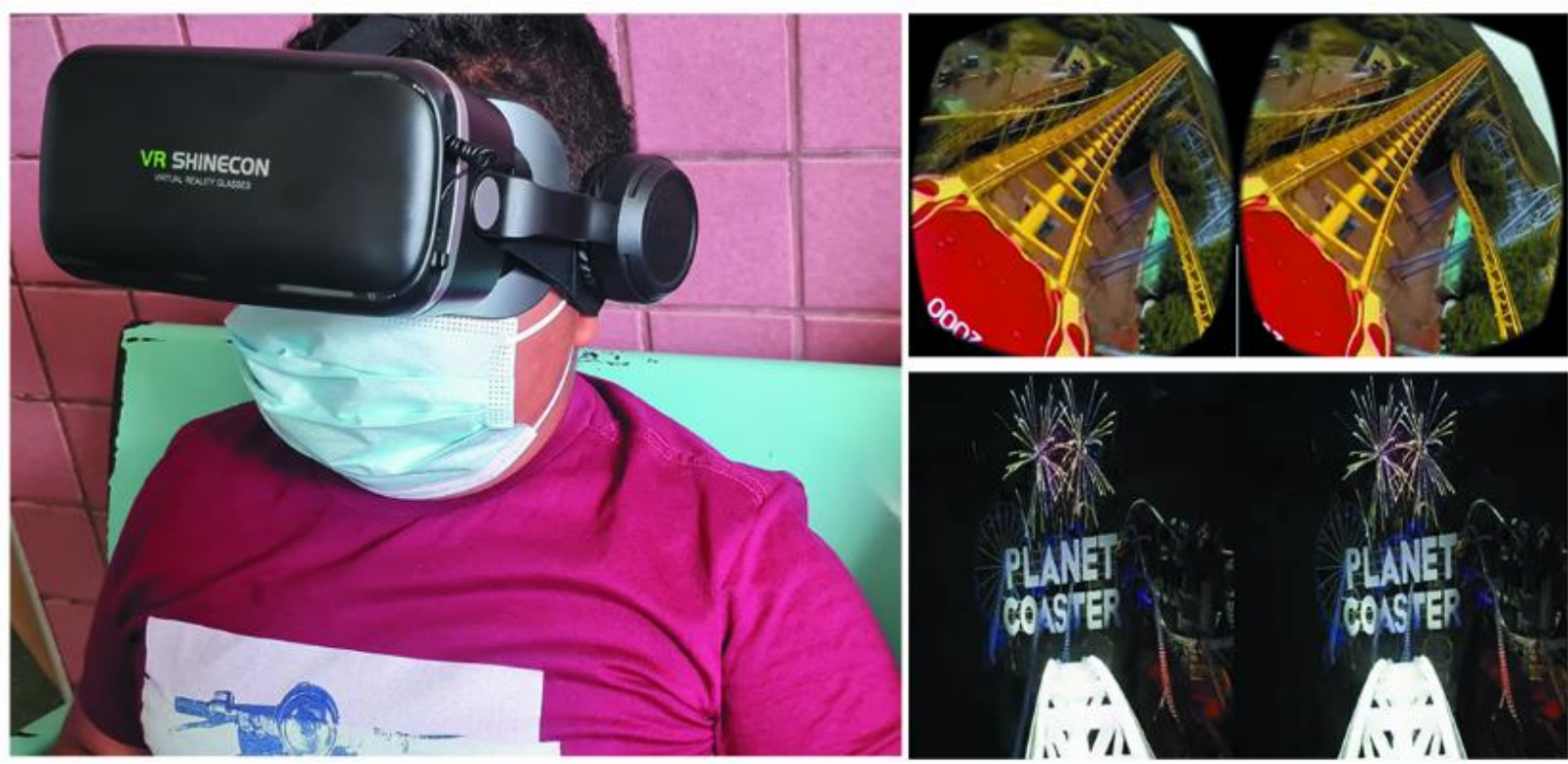

Figure 4. 3D virtual reality glasses.

\section{Mr. Tarcílio Alcântara, employee of the} Regional Integrated Oncology Center (CRIO). The famous Foguinho, the name by which he is known

According to interview with Mr. Tarcílio Alcântara, the famous "Foguinho", employee of the Regional Integrated Oncology Center (CRIO), he reports that: CRIO has become a reference center for pediatric radiotherapy in the state of Ceará. Dr. Igor Veras is the physician responsible for children's radiotherapy, and he and his team have been doing excellent work with children with cancer. The younger children need sedation performed by the anesthesiologists of the service, while the older children, most of the time, do not need any sedation. For all the children, the nursing and psychology team offers welcoming and humanization, explaining to them and their families the step-by-step of their treatment.

It is worth mentioning that a great highlight of the team is an employee: Foguinho, a born artist. He makes helmets with images of superheroes and other children's characters, and also the models of the radiotherapy room. This way, the prototype is presented to the children and they can choose their favorite characters. After the whole process carried out by the team, the children lose their fear of the procedure they will undergo and feel motivated, because they know that at the end of the treatment they will be able to take their helmets home. Little Rocket reports: "I've been doing this for ten years; Seeing the smile, the happiness, and in a way being 
able to impact the lives of children is

priceless" (Figure 5).

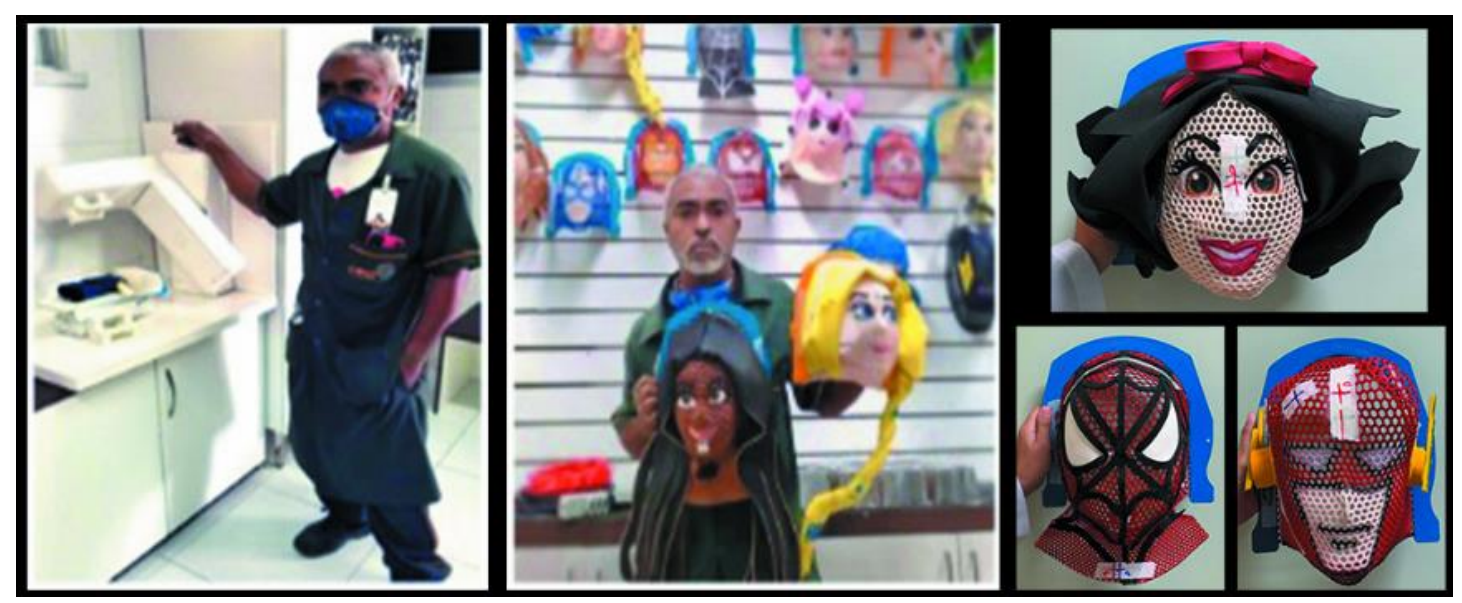

Figure 5. Panel with the helmets of the children's favorite characters and the model with a doll performing radiotherapy.

\section{Dr. Rosa Maria Benjamim de Oliveira, anesthesiologist at Hospital Infantil} Albert Sabin (HIAS)

Passionate about the world of children, Dr. Rosa Maria has always sought strategies to transform the surgical center into a playful and pleasant environment for children. She is also recognized as a professional who has developed her work in an exemplary manner. In this scenario, when faced with a challenging situation with her grandson João Lucas, who needed to undergo a minor surgical procedure, she felt motivated to create a children's story and write it, in a book entitled "The Adventures of Little Super Bean in a Hospital", which deals with the perioperative period in a playful way. In this way, children can face the moment of illness like a fairy tale: without fear and in a language easily understood by them. Dr. Rosa has kindly made some of the pages of her book available to the public through the link

https://drive.google.com/file/d/120ETgg 2etohffv8srvr7HJCoq1_Uwm6O/view.

In the book, she advises parents and health professionals responsible for children to enter the universe of play. As she wrote, children are in the world to play; however, adult concerns are best left for the future. She is very pleased to say that this book has helped many colleagues in the specialty to explain to their own children what their profession is all about. Some copies are in the pre-operative room at HIAS, where there are books, models and educational toys. In her book, 
specifically, she gives a hint of what will happen during anesthesia and also mentions the mask figure that will take children to dreamland. This mask is part of the inhalation anesthesia technique, once the child is prepared, the easier it will be to accept the anesthetic technique. This technique is considered standard for elective pediatric surgeries (Figure 6).

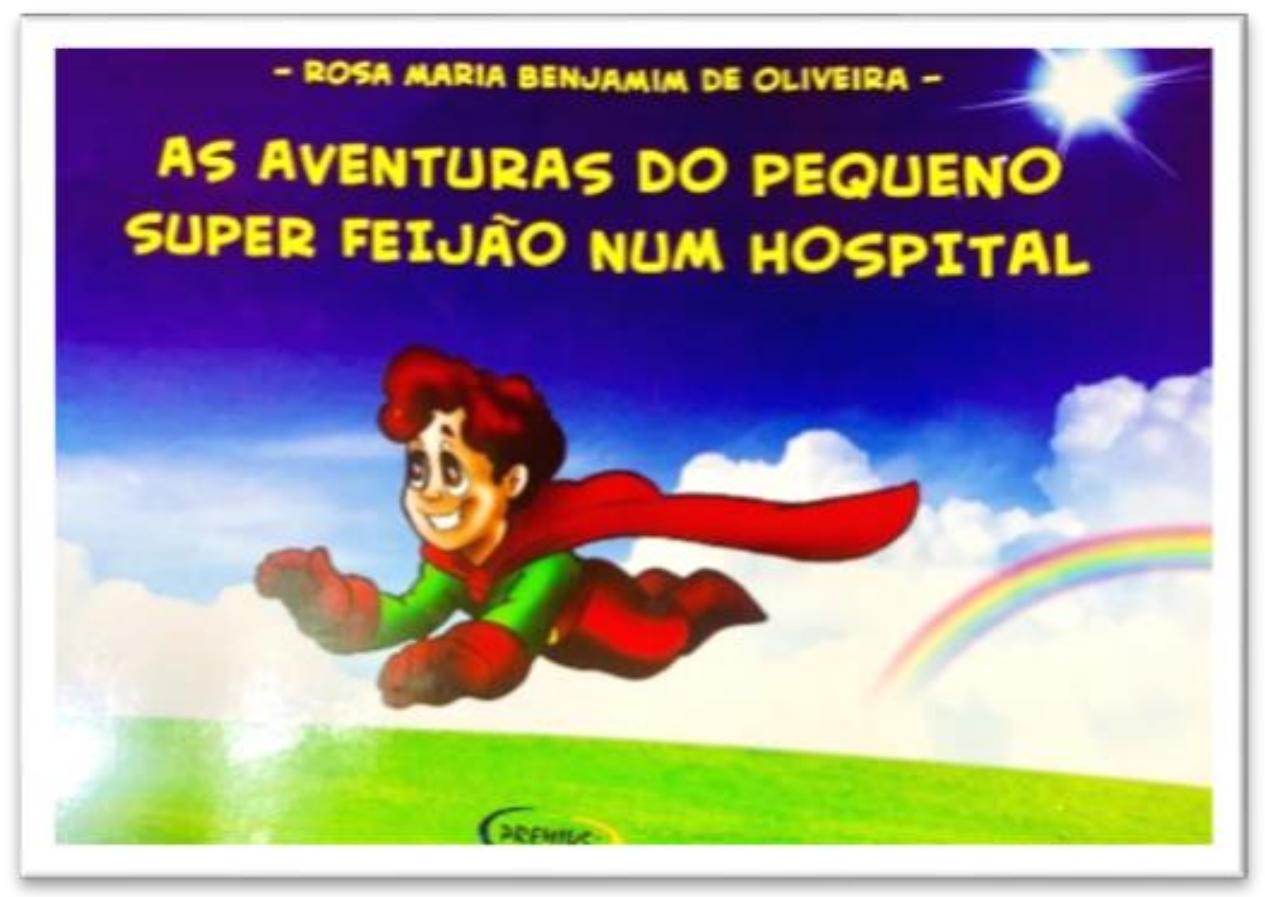

Figure 6. From the cover of the book authored by Dr. Rosa Benjamin, or Dr. Rosinha, as she likes to be called.

Dr. Washington Aspilicueta Pinto Filho, MD, anesthesiologist, pain and palliative care clinician at HIAS and Pediatric Cancer Center

According to him, anesthesiology has been assuming an increasing importance among the medical specialties, and what most calls attention in his routine is the polyvalence of this specialty. An anesthesiologist is a doctor who takes care of health problems from newborn children to centenarians in the surgical unit. However, there are anesthesiologists who dedicate themselves almost exclusively to pediatrics. In 2006, he started his work in pediatric anesthesia. He points out that it is necessary to improve the hospital routine so that the children cared for have greater safety.

During a service with an autistic child, he felt the need to establish a specific conduct for those patients, however, everyone would need to work 
together. At that moment the child was extremely agitated, impossible for any stranger to approach. A previous programming was needed, like something to be organized in an ambulatory, with joint action between surgery, anesthesia and the pediatric specialty. According to Dr. Washington, "our motivations are based on the problem that bothers us the most, it's like a pebble in our shoe, it only stops bothering you when you remove it". Based on this, and on the need for HIAS and all the team to speak the same language and apply assertive conducts, he elaborated, along with the entire HIAS team, the book "Preoperative Routines in Pediatrics". And, according to him, after the creation of the book there was a significant improvement in multiprofessional care.

This book can be downloaded for reading through this link: https://drive.google.com/file/d/120ETgg 2etohffv8srvr7HJCoq1_Uwm6O/view.

In this context, as is seen in the chapter headings of the book, virtually every specialty in pediatrics has contributed to establishing goals of perioperative care, from management of children with airway infection to children with agitation disorders, as is common in autism. In short, it can be said that information is a valuable weapon for making progress in the care of our children (Figure 7).

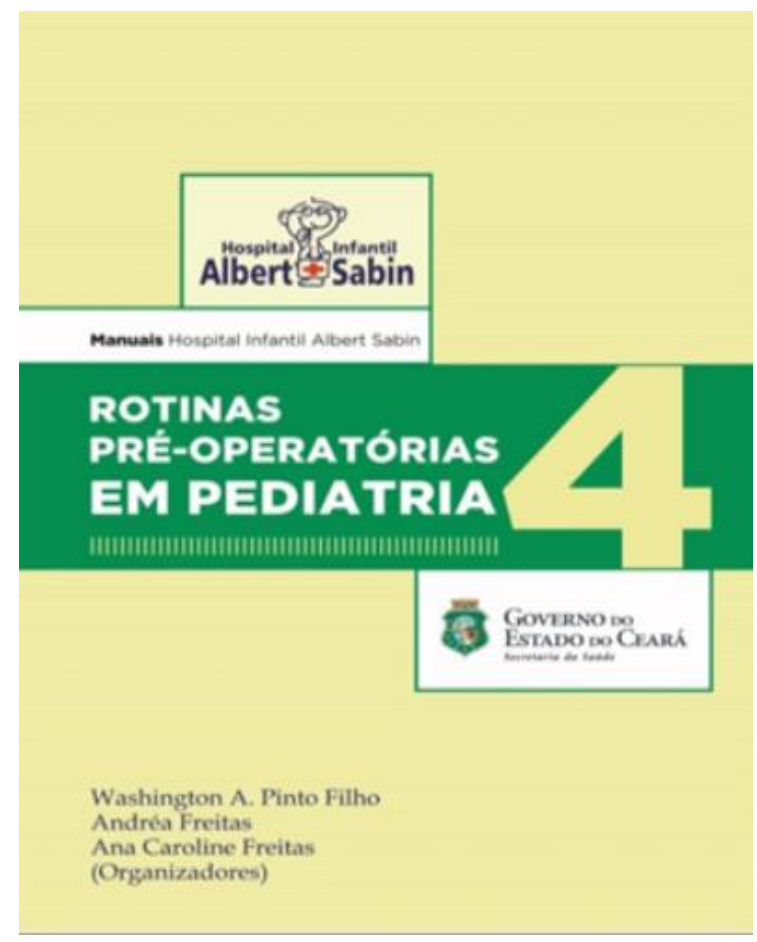

Figure 7. Cover of the book Rotinas Pré-operatórias em Pediatria. 


\section{Discussion and Conclusion}

Despites of medicine evolution, medical practices encourage constantly modifications and adjustments to promote satisfaction for our children. The health professionals include according to each area of expertise their best acquaintance. In pediatrics, the humanization of care turns a greater challenge due to the peculiarities of this public. Avoiding future traumas, the simple and technological toys and books have been used as technical games capable of making anesthesia easier in these patients. These actions became more humanized and reducing stress for children. In this context, the anesthesiologist, among other professionals, promotes the best care and comfort for children and families [2].

Closely care is the key element in humanized approach, which was mainly mentioned by healthcare providers who might have been more familiar with this medical concept than patients and their caregivers. The concept refers to the need to take into account all the biopsychosocial and spiritual dimensions of the patient, disease, and care, and to see the patient as a biopsychosocial being. Such an approach recognizes that the mind has a strong impact on the body and that we need to ensure a form of care that addresses both body and mind in order to be effective, especially in pediatrics care [3].
We conclude that is possible news approaches improve the good care in children, and the health professionals have expertise and knowledge to innovate his practice.

\section{References}

[1] Norris S, Minkowitz S, Scharbach K. Pediatric Palliative Care. Primary care. 2019;46(3):461-73.

[2] Lauro HV, Haines FE. Pediatric anesthesia safety: then and now. Anesthesia and analgesia. 2012;114(6):1163-5.

[3] Busch IM, Moretti F, Travaini G, Wu AW, Rimondini M. Humanization of Care: Key Elements Identified by Patients, Caregivers, and Healthcare Providers. A Systematic Review. The patient. 2019;12(5):461-74.

Conflict of interest: The author declares no conflicts of interest.

Acknowledgements: None.

Funding: None.

How to cite this article: Arruda LGOC, Marília Freitas Santana, Barbosa GS, Lima AM, Veras IM, Souza LCB, Maia FL, Castro RJA, Collares DM, Gomes JMA. Innovation and humanization in child care: professionals from Ceará who make the difference. Brazilian Journal of Case Reports. 2021 OctDec;01(4):114-123. 